\title{
APPLICATION OF SWAT MODEL IN ASSESSING THE IMPACT OF LAND USE CHANGE IN RUNOFF OF MAROON RIVER IN IRAN
}

\author{
Shafiei Motlagh, K. ${ }^{1}-$ PoRhemmat, J. $^{2 *}-$ SedGHI, H. ${ }^{1}-$ HoSSENI, M. ${ }^{2}$ \\ ${ }^{1}$ Department of Water Resource Engineering, Science and Research Branch, Islamic Azad \\ University, Tehran, Iran \\ ${ }^{2}$ Hydrology and Water Resources of Soil Conservation and Watershed Management Research \\ Institute (SCWMRI), Tehran, Iran \\ *Corresponding author \\ e-mail:porhemmat@scwmri.ac.ir
}

(Received 21 ${ }^{\text {st }}$ Feb 2018; accepted $17^{\text {th }}$ Jul 2018)

\begin{abstract}
Proper management of watersheds is one of the most important methods for using water and soil resources. In the last few decades, accurate and timely estimates of the quantitative and qualitative runoff status are one of the major concerns of large-scale management. The aims of this research are a simulation of monthly runoff, sensitivity analysis, optimization of sensitive parameters, investigation of the effect of land use change over the last four decades on the quantity and quality of the Maroon River (southwest of Iran) at the exit point of the Maroon Watershed (Idnak) in Iran using the SWAT model. For this purpose, the semi-distributed SWAT model and the SUFI2 program were used in the SWAT CUP software package for sensitivity analysis, calibration, validation and uncertainty analysis. In this research, the map of land use change and soil mapping and vegetation cover in the Maroon watershed were first identified over the course of the four decades between 1970 and 2010, using TM and ETM satellite measurements in Landsat. Observations of the Idnak Hydrometer Station were used as the base station during 1970 to 2010 over a period of four decades. Comparison of the effects of land use management options on various components of the hydrological cycle as well as different runoff rates show that if the pessimistic scenario occurs, and with the continuation of the destructive trend in land use to the retreat, values of runoff will increase and there will be more permeability and the drainage will go down to deeper aquifers.
\end{abstract}

Keywords: watershed, SUFI 2, management, Iran

\section{Introduction}

The proper management of watersheds is one of the most important methods for optimal use of water and soil resources. For this purpose, comprehensive information of different methods of management and executive is needed. In our country, more catchments, especially mountainous watersheds lack sufficient numbers of measurement stations which will cause any development planning and management schemes to fail. To tackle this issue, practitioners and researchers in water and irrigation management have offered solutions such as empirical formulae and mathematical models. So far, no optimal solutions have been provided. It is believed that simulation of hydrological phenomena of basins could be the optimal solution (Rostamian et al., 2010). During the past few decades, correct and timely estimates of the quantity and quality of runoff are one of the concerns of senior management. Watershed management, water resources management, especially management of reservoir exploitation and water supply network are faced with challenges. Generally, to understand and predict the processes of generation and transmission to the output stream basin is one of the most fundamental discussions in 
hydrology (Salmani, 2011). Rainfall-runoff simulations are one of the key issues considered in hydrologic sciences and environmental management. In recent years, the need for water is growing rapidly. There is an increasing demand for water resources to integrate, sustain and manage basins as well as the proper understanding of water balance in basins (Anwar, 2010). Therefore, hydrologic models have been developed to simulate rainfall-runoff, river flow analysis and to better understand the factors affecting the hydrological cycle in watersheds (Alavinia et al., 2010). These basin hydrological models are vital tools to better understand different hydrological processes, to optimize management strategies and evaluate the impact of land use changes in different time periods (Spruill et al., 2000). In these models, studying the processes of rainfall - runoff is difficult and there are uncertainties due to the influence of various parameters. These models are accurate in predicting the hydrological response of basins and can be improved with localization of optimal parameter values (Karlinger et al., 1988). The purpose of the model is to find, and as a representational image, to simply represent the facts and phenomena. The mathematical model describes the behavior of a system mathematically. These models have many applications, especially in the natural sciences and engineering systems (Mirabzadeh et al., 2005). Due to the temporal and spatial variations in the water cycle factors affecting natural watershed, identifying all components through analysis or theory of the water cycle is often impossible and time consuming. Hydrological models have been developed to overcome this problem and have been used in watersheds around the world. Since the results of some of these models matched the actual values, there has been an increase in using these models in watershed studies. With access to distributed spatial information, distributive hydraulic models are increasingly used to simulate the various hydrological processes in order to identify and manage natural and human activities that affect the watershed systems (Zhang et al., 2008). SWAT is a model in catchment basin scale that is provided by Jeff Arnold. The SWAT model is a multi-purpose simulation model for watershed management. This model is developed using several other models to estimate and predict the impact of different land management practices on water levels, sediment and chemical-agricultural watersheds within complex and large data without soil, land use and conditions management in the long run. This model has been used successfully to simulate the runoff, sediment and nutrient loads to many basins throughout North America, Asia and Europe (Duan, 2009). The review of the Omani studies showed that to predict the effects of changes in land use and conservation activities on the amount of suspended sediment Gharehsou basin with an area of $5739 \mathrm{~km}^{2}$ using SWAT2000, this model can be used as an effective tool to review basin hydrological components used in response to corresponding changes in land use (Omani et al., 2007). In basins of West Africa using SWAT model caused changes of conditions in changing areas of forest, grassland and shrub land in relation to agricultural land or natural hydrology in urban areas resulting in areas becoming watershed transformations and resulting in an increase in the volume of surface runoff, groundwater resources and water-based power reduction as well as changes in the amount and intensity of river erosion and sedimentation (Liu, 2009). Wang et al. showed by modeling the effect of different land use options in a basin in China that it is evident that land use has different effects on the amount of runoff and underground water basin and converts forest land to pasture land within the basin leading to an increase in annual runoff and reduction in permeability of the soil and groundwater due to reduced transpiration reduction in basin (Willems, 2009). Palamuleni (2011) examined time changes in land cover and land use and its effects on river flow regime Prshayr during the 
two time periods (1989 and 2002). The SWAT model (Phomcha et al., 2011) showed that the result of converting forest land to pasture, farmland and residential areas are effective on the rate of runoff and concentration time $\left(\mathrm{t}_{\mathrm{c}}\right)$. Salmani (2011) simulated the effects of changes in land use on runoff in the Qazzaqli catchment in Golestan province using the SWAT model and showed that this model can be used as an effective tool in the study of the hydrological basin Qazzaqli catchment in components used in response to changes in land use (Salmani, 2011). Land use changes in a basin could significantly impact the hydrological cycle and water resources in the basin, therefore effects of land use changes on watershed hydrology are a guideline to determine appropriate strategies for sustainable development of water resources within a watershed. Natural earth ecosystem exploitation along with changes in land cover and land use especially in ecosystem environmental conditions affect hydrological responses to such as floods, erosion and sedimentation. Land use and land cover is one of the main factors in water resources management, erosion, and sedimentation basin. This complexity is not easy to study and analyze. Considering the importance of the subject and to aid in improved management of water resources, this study will utilize the Maroon Basin model and will be provided with SWAT as semi-distributed hydrological model. Accordingly, weather, soil, topography, observational discharge outlet of the basin, changes in land use and types of vegetation factors affecting the quantity and quality of water resources at the basin scale will also be investigated.

\section{The studied area}

Maroon basin is located in the southern and south-western domains of Central Zagros $50^{\circ} 05^{\prime}$ East longitude and North latitude are $30^{\circ} 39^{\prime}$ and $31^{\circ} 21^{\prime}$, respectively. The study area is supervised by the Regional Water Company in Kohgiloyeh and Boerahmad Province. The area of this range is $3801 \mathrm{~km}^{2}$. The maximum height of this area is $3403.4 \mathrm{~m}$ and the minimum is $397 \mathrm{~m}$. The highlands area is $3703.8 \mathrm{~km}^{2}$ and the plain area is $196.9 \mathrm{~km}^{2}$. The average height in highlands is $1689.22 \mathrm{~m}$ and in plains it is $984.32 \mathrm{~m}$ (Water Resources Management Co of Iran, 2009). The climate of the affected area is of low latitude with elevation changes, and is adjacent to the Persian Gulf in the southern areas. The geology of Maroon basin consists of outcrops of sandstone, conglomerate and alternation of colored marl and silty limestone. The type of precipitation at higher elevations is in the form of rain and in the form of snow at lower altitudes. Average annual precipitation in this basin is $150 \mathrm{~mm}$ in the coastal plains, and $900 \mathrm{~mm}$ in elevations. Figure 1 shows the location of the studied area that is characterized by 7 sub-basins with numbers 1-7.

\section{Materials and methods}

The SWAT model is a continuous and semi-distributed physical model that is used to simulate complex hydrological processes in watersheds with respect to changes in soil, land use and weather conditions for long periods of time. This model requires comprehensive information, including topographic maps, digital elevation model (DEM), land use, utilized soil properties, management information, meteorological data and other watershed characteristics to simulate watershed hydrological process. The topography defined by a digital elevation model (DEM) represents the height of each point in each region with specific spatial resolution that is displayed by a cellular network. DEM map of the area with 1: 50000 scale is provided by the Forest 
Rangelands and Watershed Organization. Geographical coordinates were then entered into the model. In this study, the DEM map is used to specify the basin and sub-basins surface drainage pattern analysis. Sub-basin parameters such as length and width of the channel slope are extracted from the DEM map. Maroon watershed DEM map is shown in Figure 2.

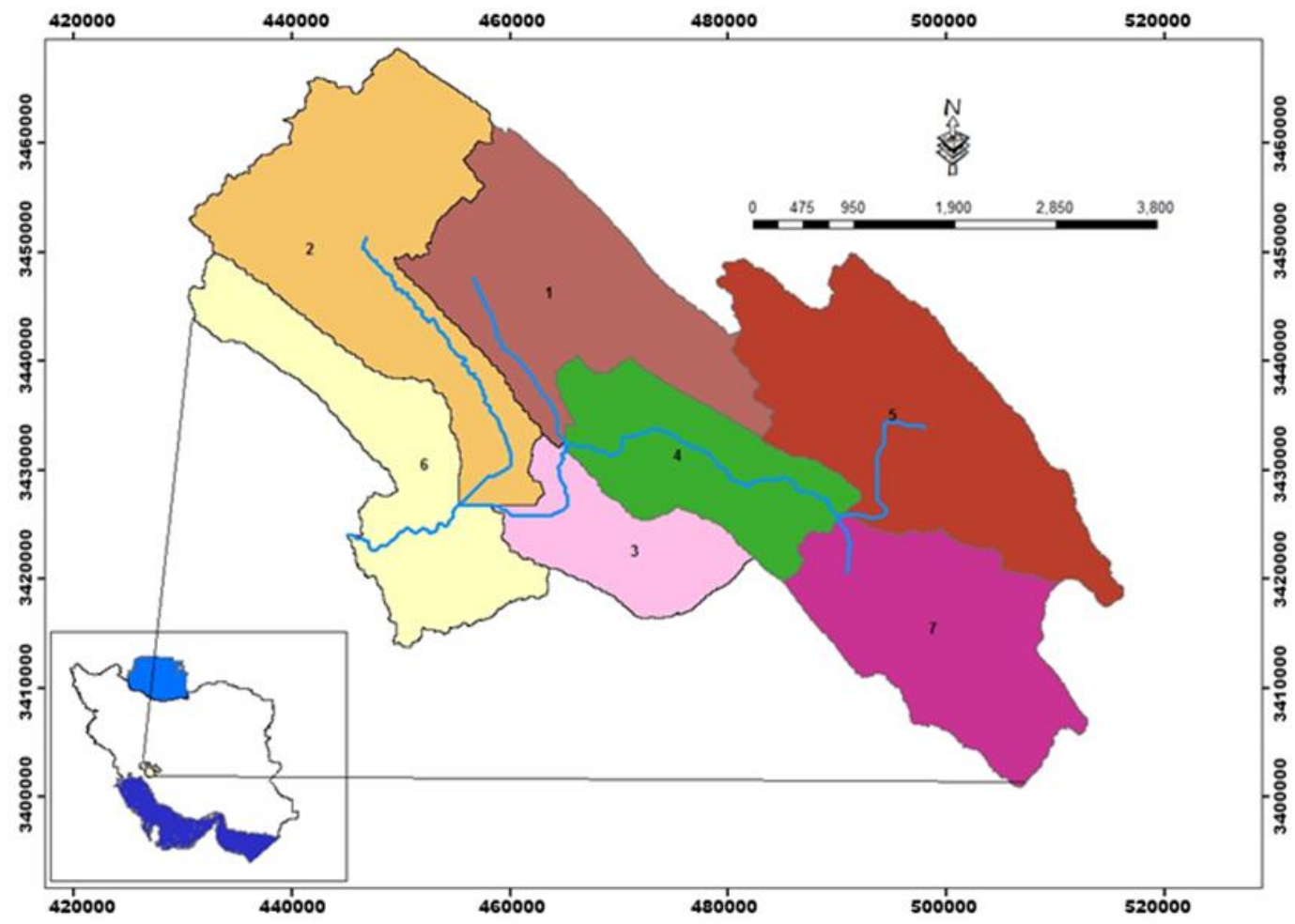

Figure 1. Location of the studied area in the southwest of Iran

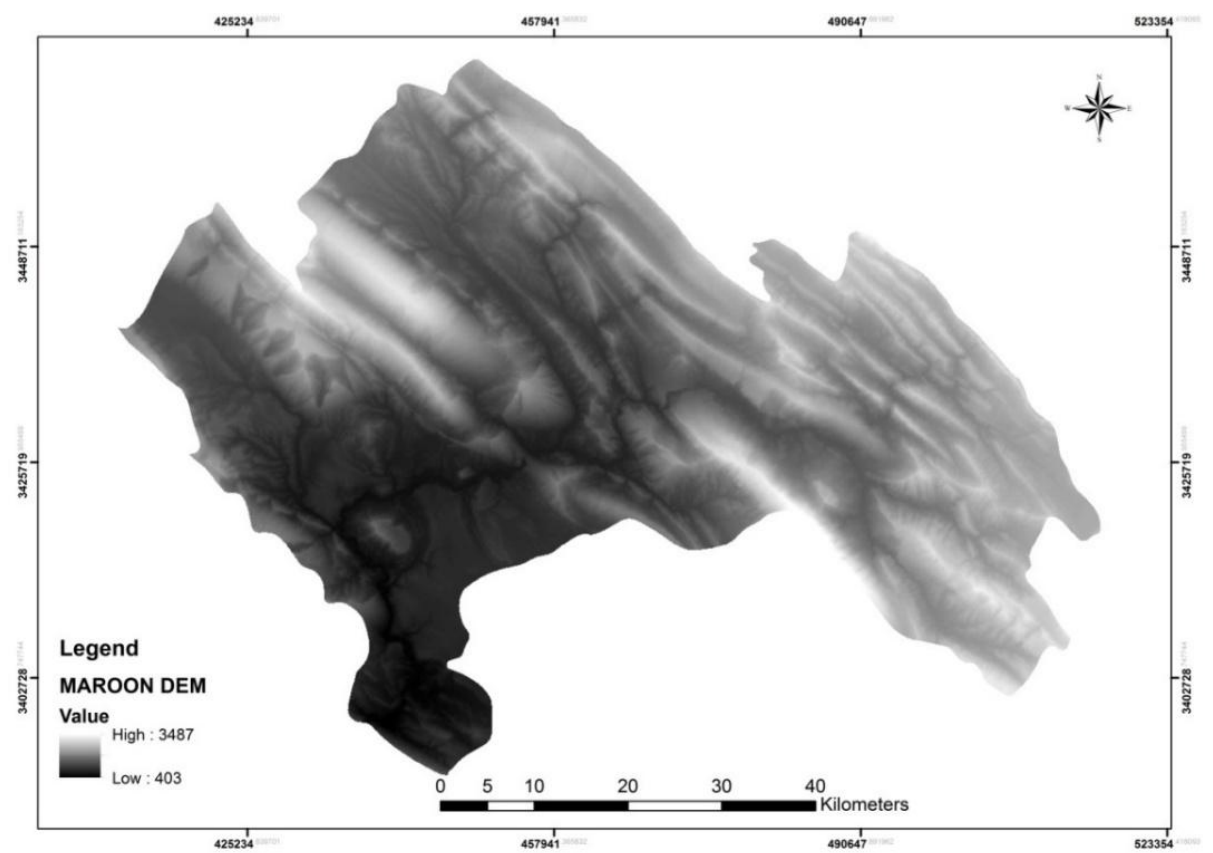

Figure 2. DEM map of the catchment area of Maroon 
Digital River network with SHAPE file format was introduced to the model as shown in Figure 3. The database of drainage network is added to the DEM map to determine the state of the river network. Map drainage network is used to draw more precise drainage pattern details in the event that the DEM basin used is not able to specify this pattern.

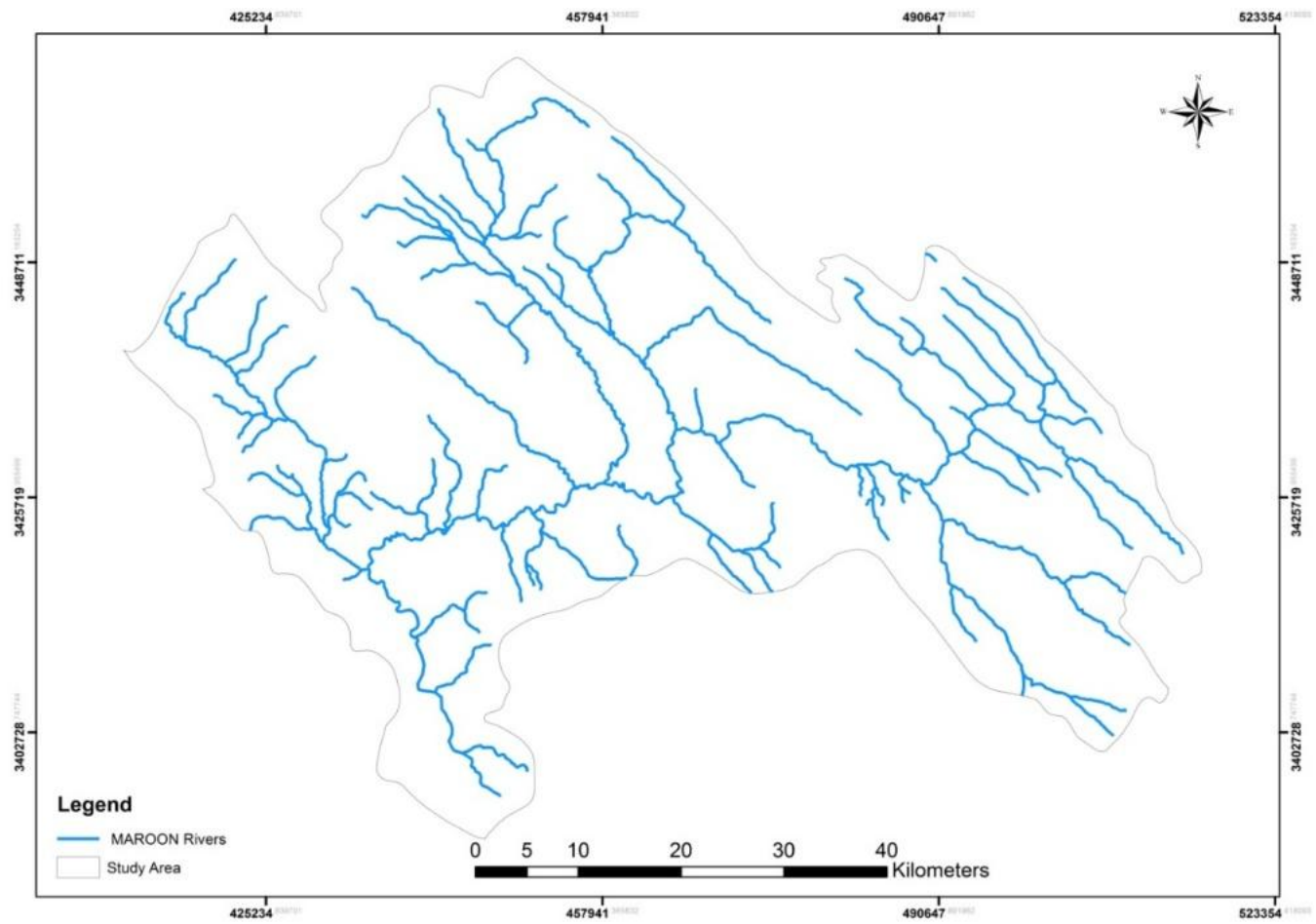

Figure 3. Network River Maroon Basin

One of the requirements for each hydrological basin simulation is the map of land use and vegetation. In the simulations with the SWAT model, the land use map is one of the essential items. Land use is one of the most important factors that affect the amount of runoff, evapotranspiration and surface erosion in the basin. Land cover information is important for many activities including land use planning and land management. Nowadays, satellite images and remote sensing techniques have been widely used in land use mapping to provide updated data, high capability analysis, variety of forms, digitization and processing in all sectors, including agriculture, natural resources and land use mapping as base maps. In the current study aimed at extracting Maroon watershed land use, initially, the images of land sat satellite for 1980-1990 and 20002010 were prepared. Then, topographic map digitization and mosaic, slope maps, aspect and elevation from sea map were prepared to identify the area in GIS software. Subsequently, correcting and processing operations on satellite images using 30 ground control points were done using Geomatica software. Furthermore, the supervised classification map of the area was produced by combining bands $3,4,5$, and the final map was obtained after applying the filter operation. Type of land use with a four-digit code can be identified by the model. Land use map of the study area was classified again by the SWAT model as shown in Figures 4, 5, 6 and 7. Land use changes per hectare during four decades clearly shown in Table 1. 


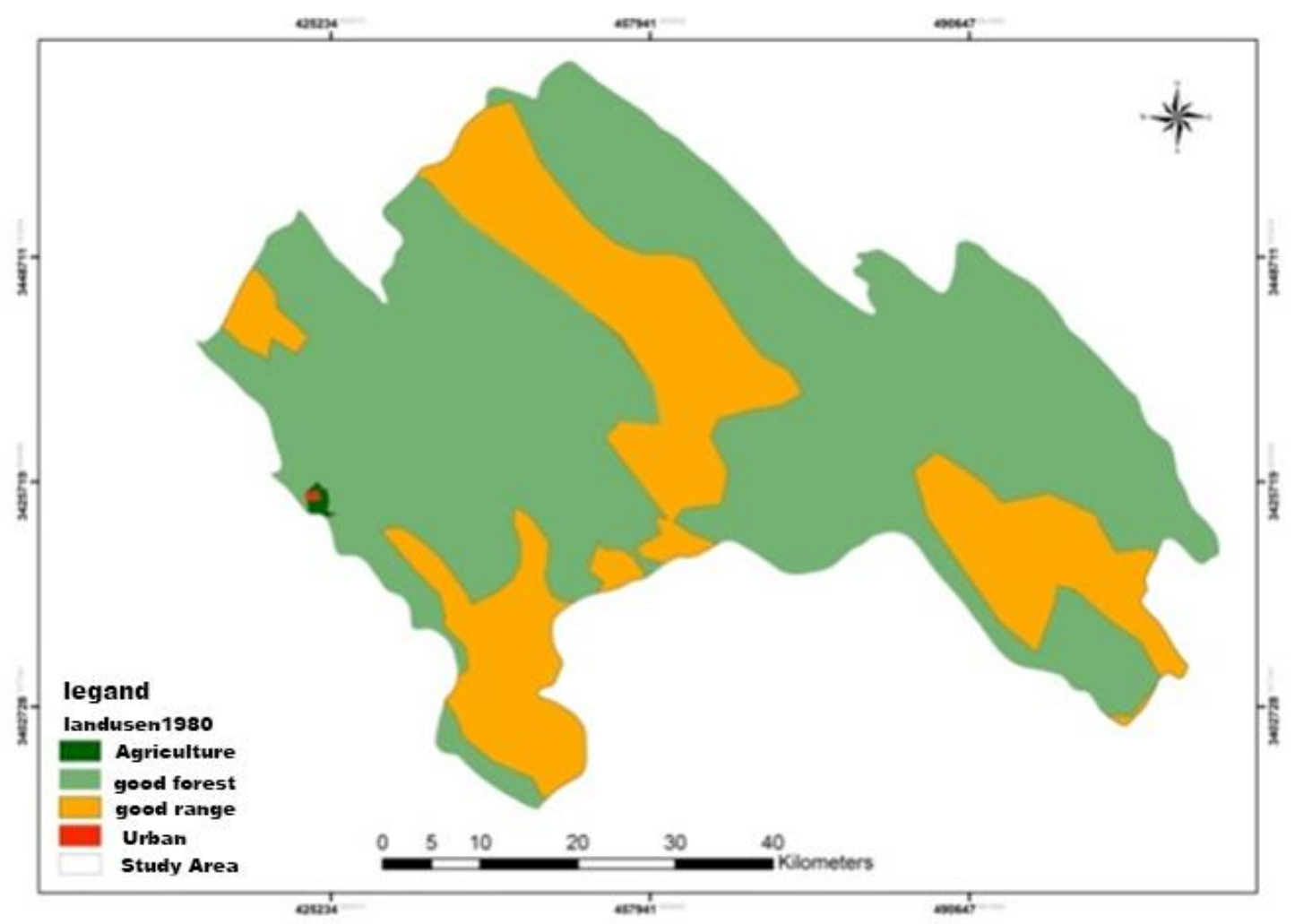

Figure 4. Land use map (1980)

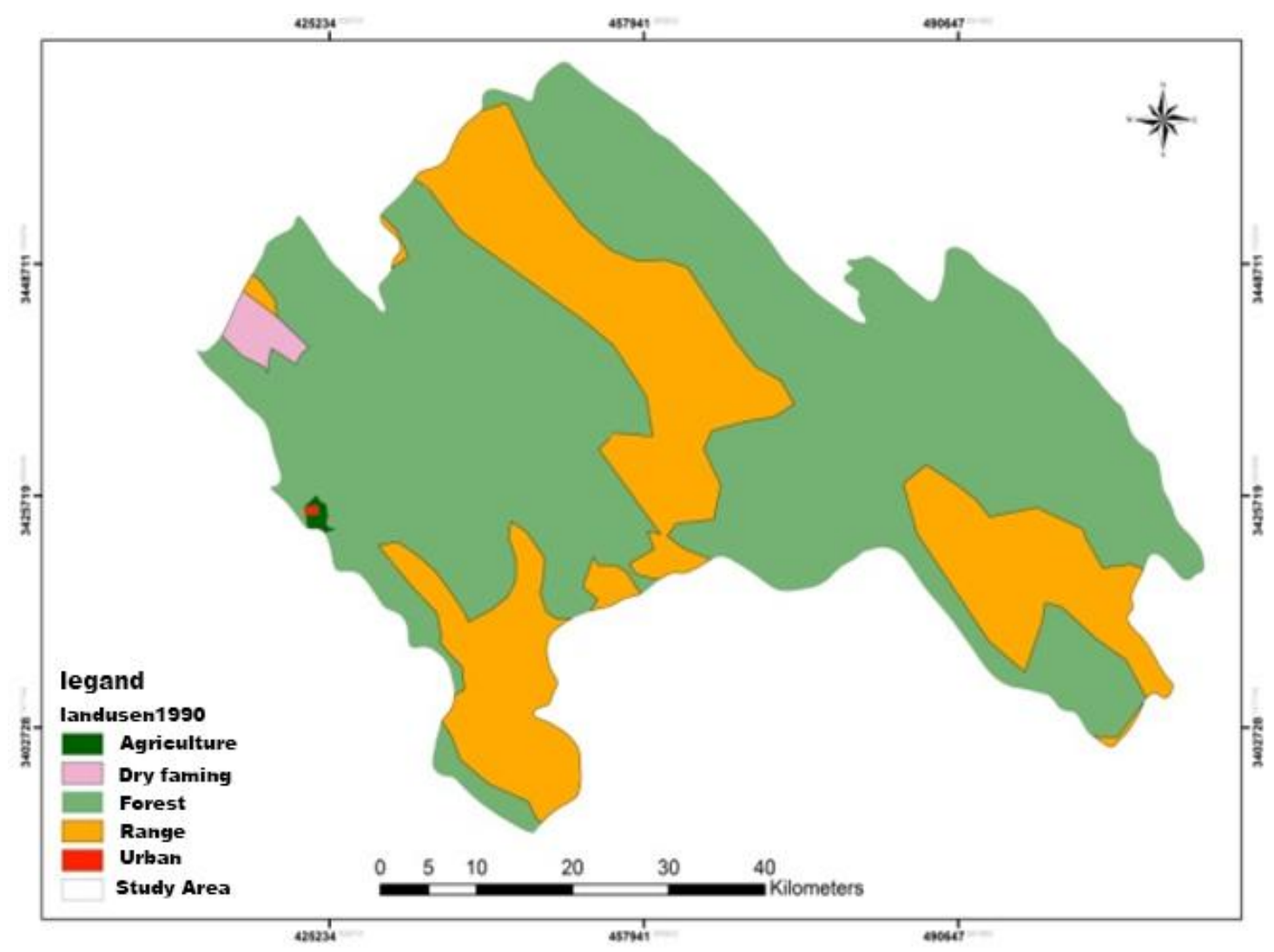

Figure 5. Land use map (1990)

APPLIED ECOLOGY AND ENVIRONMENTAL RESEARCH 16(5):5481-5502. http://www.aloki.hu • ISSN 15891623 (Print) • ISSN 17850037 (Online)

DOI: http://dx.doi.org/10.15666/aeer/1605_54815502

(c) 2018, ALÖKI Kft., Budapest, Hungary 


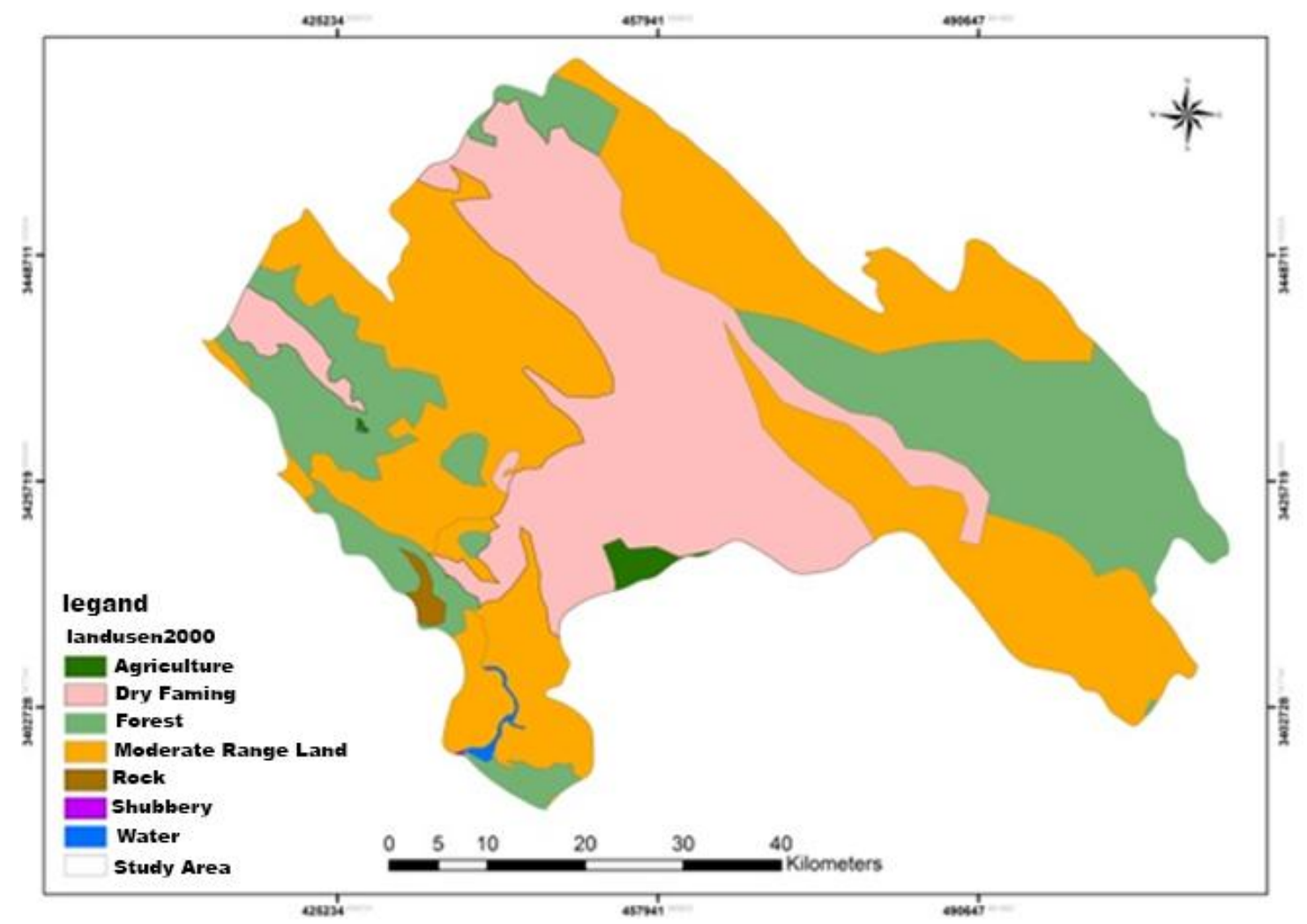

Figure 6. Land use map (2000)

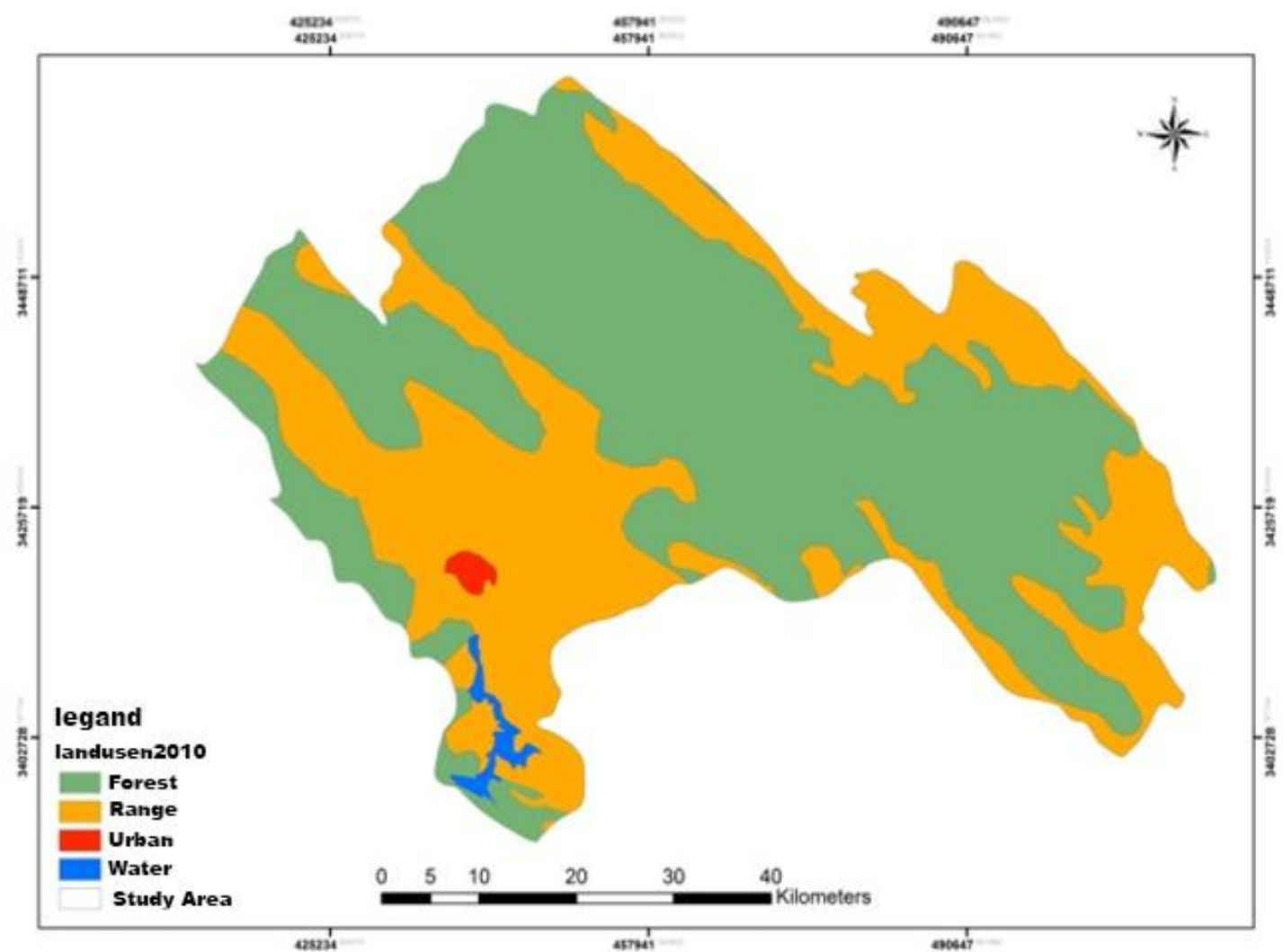

Figure 7. Land use map (2010)

APPLIED ECOLOGY AND ENVIRONMENTAL RESEARCH 16(5):5481-5502. http://www.aloki.hu • ISSN 15891623 (Print) • ISSN 17850037 (Online) DOI: http://dx.doi.org/10.15666/aeer/1605_54815502 (c) 2018, ALÖKI Kft., Budapest, Hungary 
Table 1. Land use area changes in Maroon during four recent decades/ha

\begin{tabular}{c|c|c|c|c}
\hline Use type & 1980 Use & 1990 Use & 2000 Use & 2010 Use \\
\hline Agriculture & 535 & 612 & 916 & 1344 \\
Forest & 272258 & 264458 & 256186 & 224458 \\
Pasture & 108375 & 116097 & 123415 & 154063 \\
Urban area & 126 & 127 & 752 & 1409 \\
Water & 0 & 0 & 25 & 20 \\
\hline
\end{tabular}

\section{Soil texture map of the study area}

Soil data is the most basic information required for this model. The SWAT requires various physico-chemical properties of the soil, such as soil texture, available moisture content in the soil, hydraulic conductivity, bulk density, organic carbon content and model of different soil layers to simulate the characteristics of the basin. The map of the re-categorized soil map of the Maroon watershed land use and the map of vegetation during four decades from 1980 to 2010 were prepared using satellite images shown in Figure 8 . Considering that 100 years of time is required to change the texture of the soil and the timeframe for this research is 40 years the soil texture map is identical in four decades and the model of 2010 is used in the model.

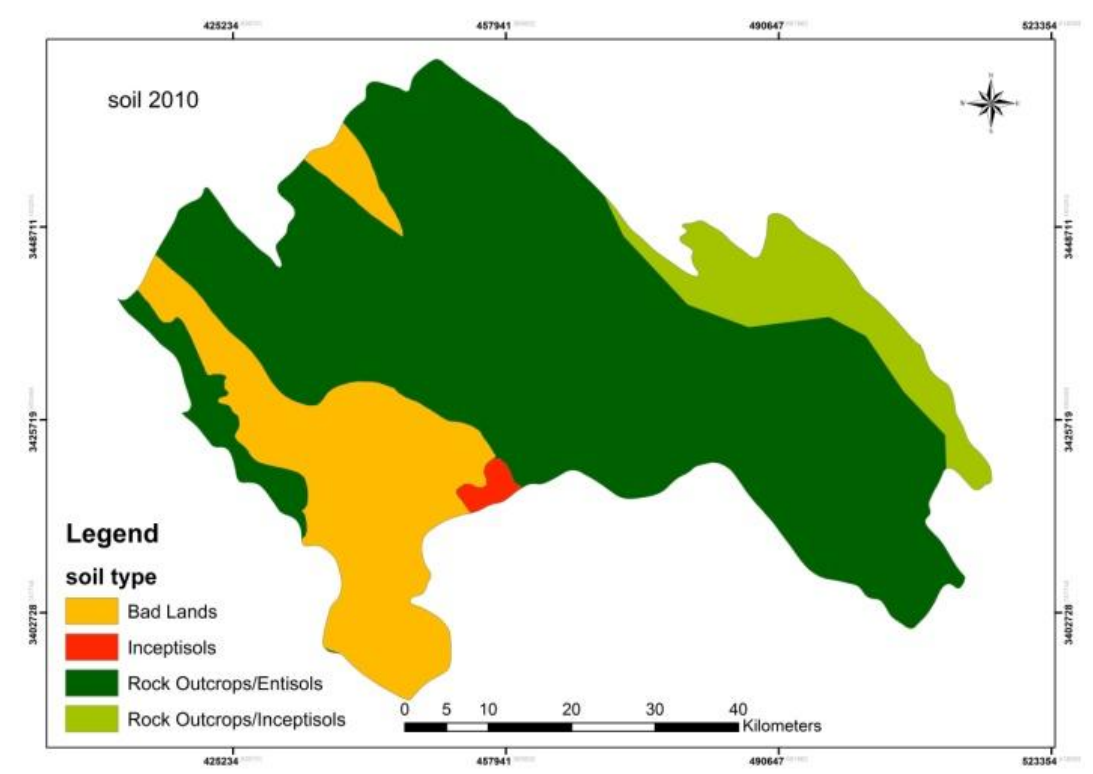

Figure 8. The soil maps of the study area during 2010

\section{Meteorological and hydrological data}

Climate as the source of input energy, determines the humidity of basins and controls water balance as well as determines the relative importance of different components of the hydrological cycle. The SWAT model requires information on basic daily climate variable rainfall, maximum and minimum temperature, solar radiation, relative humidity and wind speed for simulating the conditions of the basin. This information may be read as an input file, observational values or be created by the SWAT model by using monthly average values summarized in the weather generator input file (userwgn.dbf). 
Hydrological data are required for sensitivity analysis, calibration, and validation analysis of hydrological models uncertainty. Hydrological data used in this study consist of monthly and daily discharge values at Idnak stations located at the basin output. This data was collected from Khuzestan Province Regional Water Organization. Idnak gauging stations are used as base stations for the runoff changes. This data is converted into the format required for the model. The simulation is done automatically. Then, upon parameter optimization, the simulated value is closer into the observed data. Figure 9 shows the position and number of meteorological and hydrometric stations in the studied area.

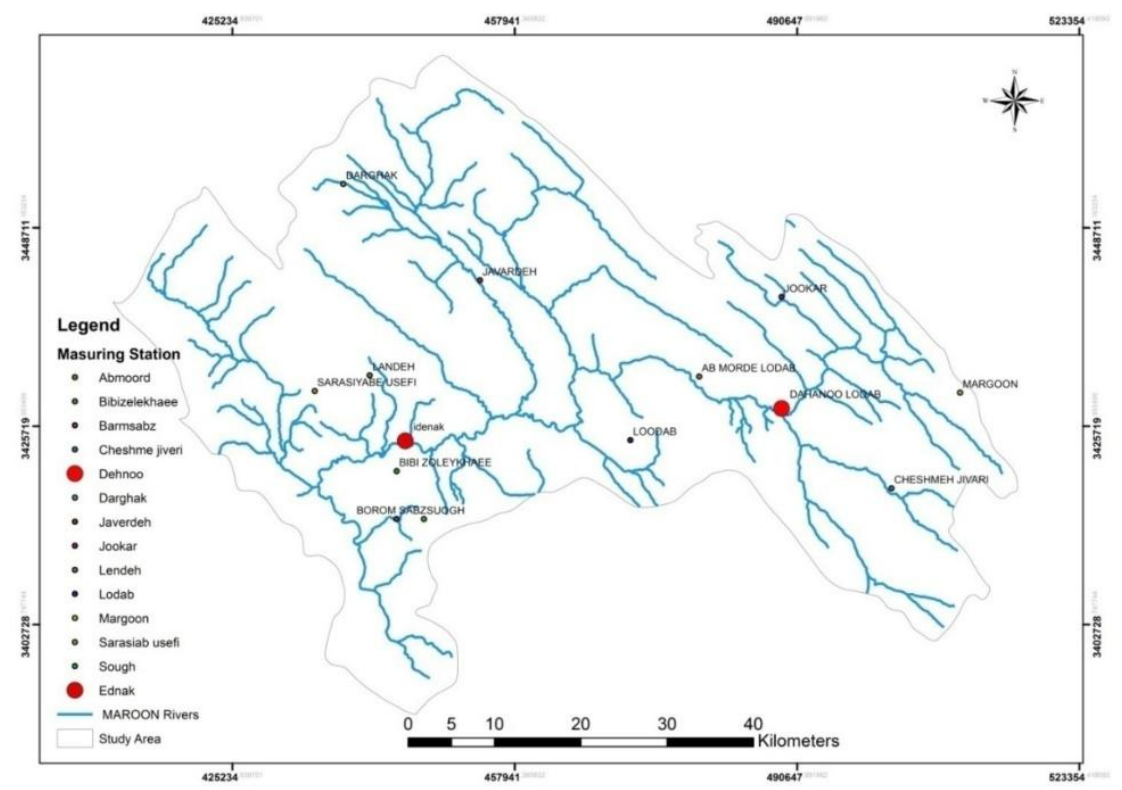

Figure 9. Position of meteorological stations in the studied area

\section{Running the SWAT 2012 model}

In this study, a semi-distributed SWAT model 2012 with a GIS extension was used for analysis and simulation. Basically, the SWAT model database is designed for the conditions of the United States of America. So to use this model in other areas the input information should be modified including data related to soil (usersoil.dbf), land (landuse.dbf), weather generator stations (userwgn.dbf) as well as management information. Data related to GIS development of the SWAT model is identified with unique functions to determine the Basin Hydrological Response Unit (HRU). The model used the data digital elevation model data to automatically divide each area based on current conditions and then accumulated the data into several sub-basins. In general, there are 25 sub-basins in the Maroon watershed with 21 sub-basin located at the outlet. Also the number 5 sub-basin with an area of $27.5 \mathrm{~km}^{2}$ is the smallest sub-basin. The sub-basin number 2 with an area of $278.36 \mathrm{~km}^{2}$ is the largest sub-basin. The hydrological response units are integrated lands that are located within the sub-basin and in the areas where land use, soil, slope and management is homogeneous and monolithic. To determine the HRU map, the gradient map was used. Different tilt classes were obtained based on the characteristics of the study area and aimed at the DEM map. According to a wide range of sub-basins in the studied area, using several 
slopes to a common dip for all sub-basins is a priority. The slope classes are different in each area depending on the characteristics of the topography of the area. In various studies done in this area, there is no single classification for slope classes. Thus, the user selects the slope classes based on topography. Generally, in the study area 4 gradient classes $(0-2,2-10,10-20$, and $>20 \%)$ were introduced to the model.

\section{The sensitivity analysis of the model}

Sensitivity analysis is the study of quantitative and qualitative changes based on input variables for Output Models. In other words, in this analysis, the effective variables ordered in the model is based on their role in the amount of general error. Maroon watershed, in terms of hydrological basin is very complex. Also sensitivity analysis was performed using the indicators t-stat and p-value SUF12 program in the bundle SWA CUP. Generally, higher absolute value of t-stat represents the most sensitive parameter. The closer the p-value is to zero, the more sensitive the parameter is. It should be mentioned that in this study, the parameter range has been set at default values for the Maroon watershed model.

\section{The calibration model}

After identifying the most critical parameters affecting the flow rate, calibration was performed to describe the optimal values. Calibration is the modification of input parameters, so that it is the best fit for the observed data. Inverse modeling in recent years is used as a suitable method in many branches of Earth Sciences and environmental studies. Maybe it is because direct measurement is time-consuming, expensive and often faced with limitations while measuring a few output parameters makes it easier for some of the input parameters (Rostamian, 2009). The calibration process may be performed in the form of trial and error methods (manually) and automatic (using computer programs). Automatic calibration is more optimal compared to manual methods and its implementation is easier (Liu, 2009). In this study, automatic calibration methods were used to identify the optimal values of model parameters. This process was done by changing the parameters specified in the input file and by using the qualitative evaluation model (Himesh, 2000). The calibration process was conducted both on a monthly and daily basis and based on the Maroon basin flow. At first, the model was simulated for a suitable period (the period of warming-up) and based on the initial values obtained for a given period which was implemented in the model. In total, 27 parameters were selected based on various studies conducted in this area that upon sensitivity analysis and identification decreased to 13 parameters, which were the most effective parameters. Reducing the number of parameters during sensitivity analysis caused reductions in the implementation time and increased accuracy by reducing the uncertainty of the model. So, after knowing the most sensitive parameter, the model was run using critical parameters affecting the discharge.

\section{Validation of the model}

When calibration is performed to check the accuracy of the calibrated model for use in estimation and subsequent management activities, the independent model using observed data was implemented (1970 and 1971 in the first decade, 1980 and 1981 in the second decade, 1990 and 1991 in the third decade, 2000 and 2001 in the fourth decade) without changing the parameters of the calibration. The model validation will 
be done to ensure that the calibration model on the output of all variables and conditions that affect calibration, correctly evaluates models of the relevant periods. Here, the same validation method and calibration process was done using the software package SWAT CUP and SUFI2program.

\section{Model performance evaluation}

To evaluate the performance of the model to simulate hydrological processes, it can be compared and simulated using different statistical models with observational data (Green, 2006). It is very difficult to only investigate one statistical method for the model's performance, therefore to evaluate the efficiency of the model; several statistical methods were used simultaneously. Williams used the correlation coefficient (R2) plus the efficiency factor Nash - Sutcliffe (ENS) proposed as a way to assess and analyze the data simulated (Willems et al., 2009). In this study, the SWAT model is used for evaluating performance.

\section{Results and discussion}

The first model was run by using input data and relevant default data. Figures 10-17 show the output in the initial run based on monthly time period. As shown in these figures, the simulated basin in the initial run is very weak. In order to check the quality of simulation in the initial run, the Nash-Sutcliffe $\left(E_{N S}\right)$ coefficients of correlation between observed and simulated values were used.

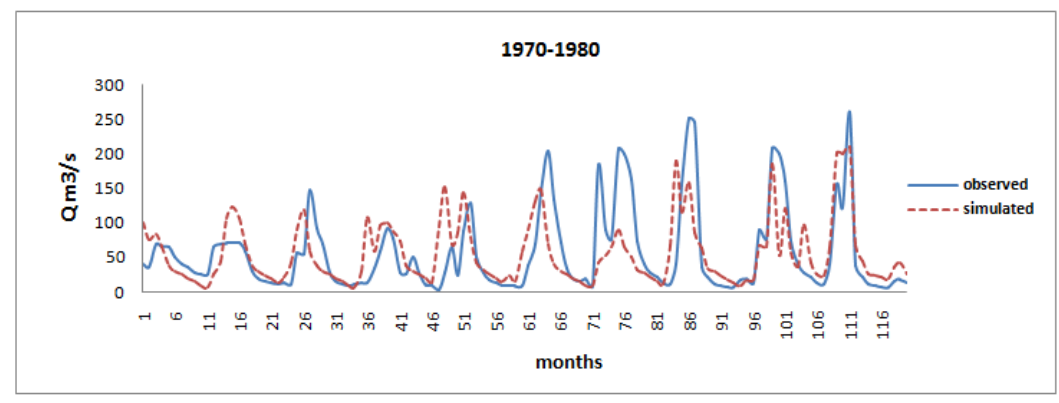

Figure 10. Values of runoff simulated and observed in the first decade of the initial run of Maroon area on a monthly basis

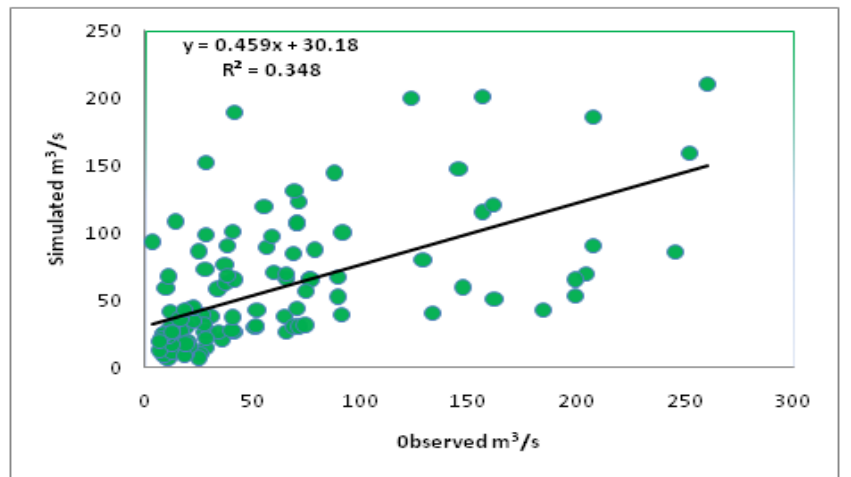

Figure 11. Correlation between observed runoff and simulated runoff in the first decade of the initial run on a monthly basis 


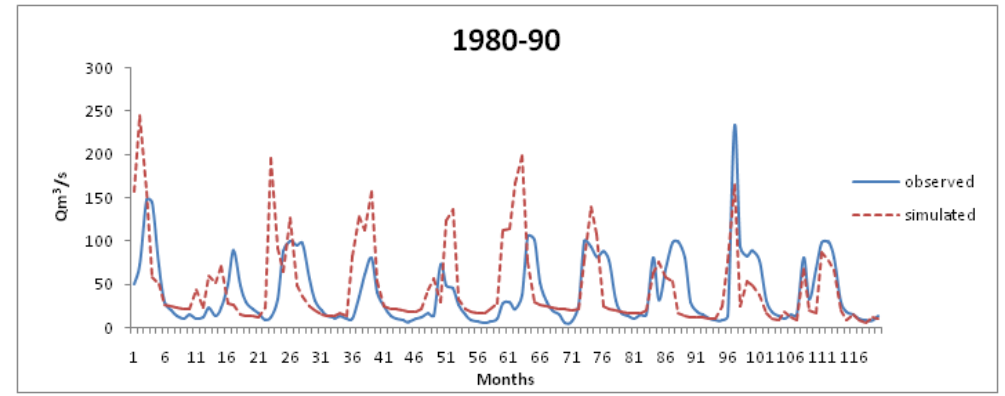

Figure 12. Values of runoff simulated and observed of Maroon area in the second decade of the initial run on a monthly basis

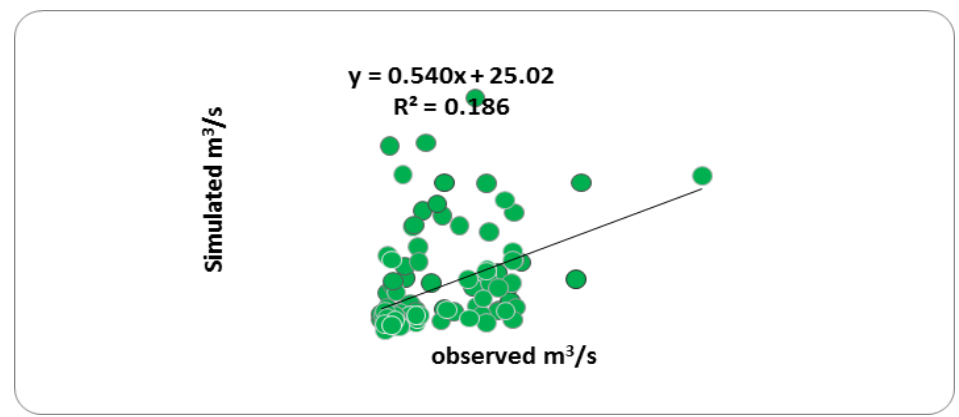

Figure 13. The correlation between observed runoff and simulated runoff in the second decade of run of the model on a monthly basis

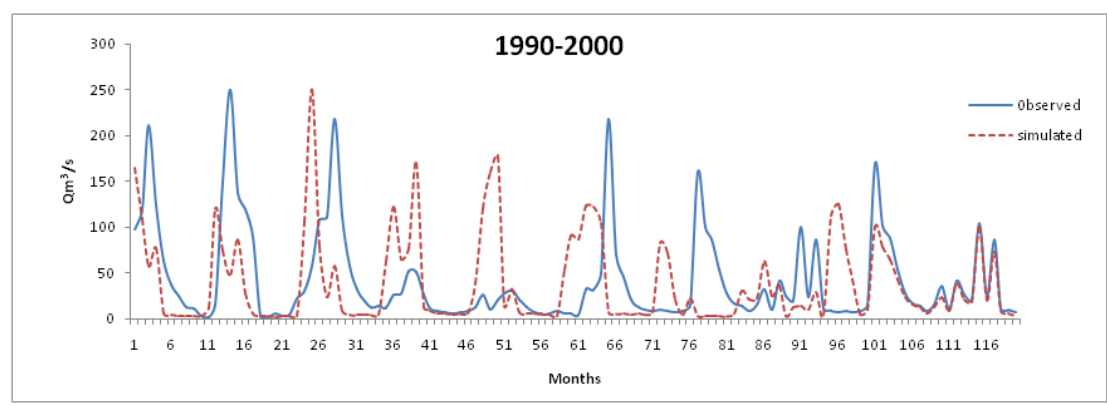

Figure 14. Values observed and simulated runoff in Maroon watershed in the third decade in the initial run the model on a monthly basis

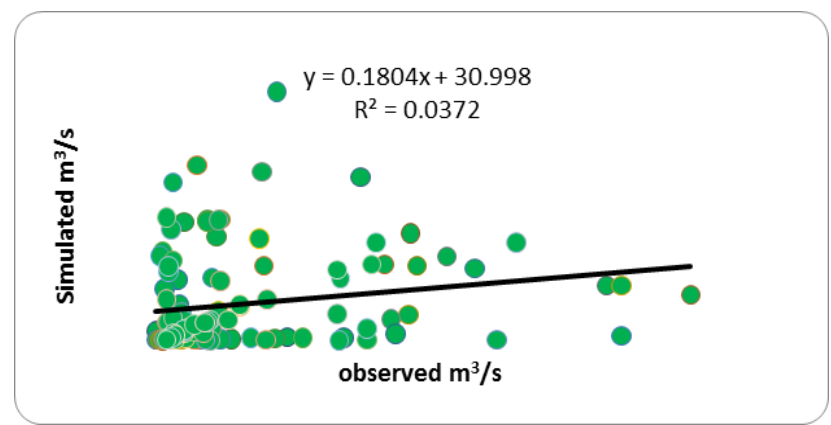

Figure 15. The correlation between observed and simulated runoff in the third decade in the initial run model on a monthly basis 


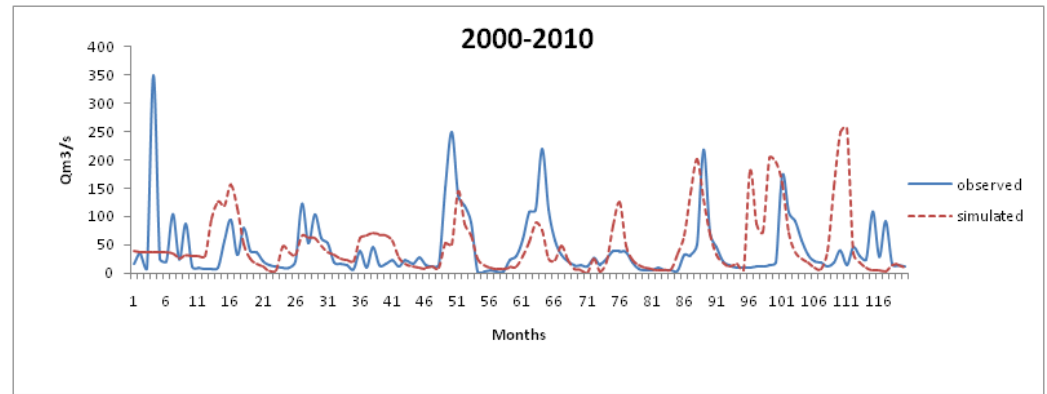

Figure 16. Values of observed and simulated runoff in Maroon watershed in the fourth decade in the initial run model on a monthly basis

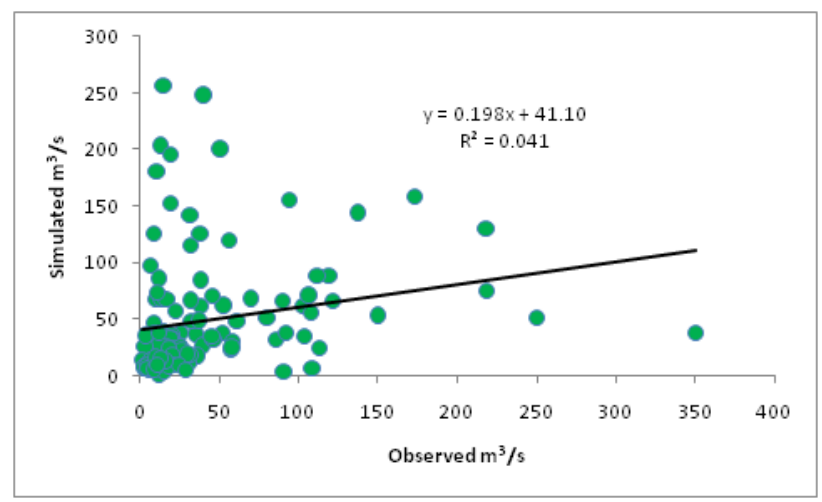

Figure 17. The correlation between observed and simulated runoff in the fourth decade of the first run model based on a monthly basis

\section{Sensitivity analysis}

After the initial run off, sensitivity analysis was carried out on the output model of the basin. In sensitivity analysis, the effect of various parameters on model output based on objective function (in this study, Nash was considered as the objective function) were clearly identified. For the sensitivity analysis and to determine the relative importance of each model parameter, the SWAT, SWAT CUP and LH-OAT methods were used in addition to the SUF12 program during calibration. Sensitivity analysis in the LH-OAT method presented is based on 27 selected parameters. Also, the identification of sensitive parameters on a monthly basis was conducted using SUF12 programs on 27 parameters as shown in Table 2.

Table 2. Priority of critical parameters based on t-stat and p-value values using the SUF12 program after calibration on a monthly basis average of the four periods

\begin{tabular}{c|c}
\hline Range & Parameters \\
\hline $20-90$ & r_CN2 \\
$0-2000$ & r_SOL_K( $)$ \\
$0-150$ & v_CH_K2 \\
$0-1$ & v_CH_N2 \\
$0-1$ & v_ALPHA_BNK \\
$10-150$ & r_SLSUBBSN
\end{tabular}




\begin{tabular}{c|c}
$0-5000$ & v_GWQMN \\
$0-50$ & v_tLAPS \\
$0-10$ & v_SMFMX \\
$0-0.25$ & r_SOL_ALB( $)$ \\
$0-500$ & v_GW_DELAY \\
$0-1$ & r_SOL_AWC() \\
$0.01-0.1$ & r_EPCO \\
$0-1.5$ & v_GW REVAP \\
$0-1$ & v_ ALPHA_BF \\
$-5-+5$ & v_SFTMP \\
$0-180$ & r_LAT TTIME \\
$0-10$ & v_SMFMN \\
$0-1$ & r_ESCO \\
$0-2.5$ & r_SOL_BD() \\
$0-25$ & v_SMTMP \\
$0-100$ & v_CANMX \\
$0-0.6$ & r_SLOPE() \\
$1-24$ & v_SURLAG \\
$0-1$ & v_RCHRG_DP \\
$0-1$ & v_TIMP \\
$0-500$ & v_REVAPMN \\
$0-25$ & r_SOL_Z \\
$0-1$ & v_BLAI \\
$0-1$ & v_BIOMIX \\
$0-10$ & v_SHALLIST_N \\
& \\
\hline
\end{tabular}

The results of the sensitivity analysis carried out using the LH-OAT method on the 27 parameters indicated that GWQMN, RCHRG-DP, CN2 SMFMN ESCO flow are the most sensitive parameters on a monthly basis. The most sensitive parameters affecting the discharge area of Maroon on a monthly basis using the SUF12 program software are SWAT CUP SOL-K, CN2 ESCO, SMFMN, RCHRG-DP, REVAPMN, GWQMN, SLSUBBSN ALPHA-BNK, excluding the most critical parameters affecting the discharge of Maroon River. In general, due to the different regional and climatic conditions, sensitive and effective parameters are different for the studied region on a daily and monthly basis (Sangjun, 2007). As seen in all methods and based on the daily and monthly activities, $\mathrm{CN} 2$ is the most sensitive parameter. The CN2 Parameter (number of CSC curve for the average moisture conditions (II) and the slope 5\%) is a function of the soil permeability, land use and former humidity conditions. The value of this parameter is different for the various soil types, land use and for each sub-basin. Generally, increasing the amount of CN2 increases runoff volume. The high sensitivity of this parameter indicates the important role of land use in the amount of runoff from the basin. Also, most of the region is mountainous, which increases the amount of runoff by reducing the amount of permeability. In this case, In this case more runoff is outside of catchment area. CH-N2 (Manning roughness coefficient of Main River) is an effective parameter on the routing of stream flow and is used to calculate the concentration of the watershed. High sensitivity of $\mathrm{CH}-\mathrm{K} 2$ (effective hydraulic conductivity river bed) in this region indicates the presence of lateral branches in the area to form intermittent or seasonal activities that impact the flow of the main river 
(Beven, 2001). This basin has rigid seasonal streams and numerous rivers, especially in semi-arid areas that in the case of rain and flooding, has considerable impact on the outflow at Idnak gauging stations. SOLK (saturated hydraulic conductivity of soil layers) is scaled to facilitate movement of water in soil layers that represent a balance between water flow and hydraulic gradient. Other important parameters on the HRU level include SUBBAN (average length of the slope of the land in each HRU) that may have the same value for each HRU as well as the ESCO parameter (evaporation from soil coefficient offsetting) which is an important parameter influencing the hydrological cycle surface. Generally, decline in this parameter increases surface runoff base flow and vice versa. ESCO reduction causes the transmission of more water from the lower layers to the upper layers of the soil and consequently the amount of surface runoff and base flow will increase. Effective parameters on groundwater are effective on surface water. These parameters show that the river flow is mainly controlled by groundwater flow. GWQMN (minimum shallow water table depth required for the reverse flow) is relevant to current production base. Considering the depth of the water in the aquifer level, groundwater flow occurs when the water level in the aquifer level is equal to or greater than GWQMN. This parameter has an impact on base flows and affects the flow of the river (Reungsang et al., 2005). RCHRG-DP (recharge percentage deep aquifer from shallow or confine aquifer) represents the percentage drop of water from the root zone that feeds the deep aquifers. The high sensitivity of this parameter in the studied area entails the probability of water transfer from the shallow aquifer to the deep aquifer and may create problems in water balance and consequently for the region (Sanjay, 2010). REVAPMN (minimum depth of water table levels in shallow aquifers to climb through the capillary or recharge deep aquifer) is representative of the water movement to the unsaturated zone and deep aquifers. ALPHA-BMK (alpha factor for storing base flow the sidebar) represents the side which is affected on the main channel or sub-basin within the range.

\section{Model calibration}

After the initial run the SWAT CUP software package and SUF12 programs were implemented for calibration and uncertainty analysis to determine variable Maroon River discharge areas in the basin outlet. According to various studies conducted in this field, about 27 parameters are effective and important for calibration. Varying ranges of parameters were set according to their default model and based on hydrometric station of Idnak. Each parameter was entered in the model within the limits of permitted changes, and implemented in order to optimize the output of the simulation model. Then, sensitivity analysis reduced the number of parameters. A total of 13 known parameters from the 27 selected primary parameters were more effective and were entered in the final stage of the model. Calibration was performed on a monthly basis during various stages for various parameters. Finally, the optimal values of parameters were determined to simulate the monthly watershed runoff. Table 3 shows optimal values of parameters that affect the rainfall-runoff (amount or percentage changes) upon simulation and calibration of the parameters after the 2000 runoff model. Also Figures 18-25 show calibration results based on a monthly time period using the SUF12 program and also the correlation coefficient between observed and simulated runoff model. 


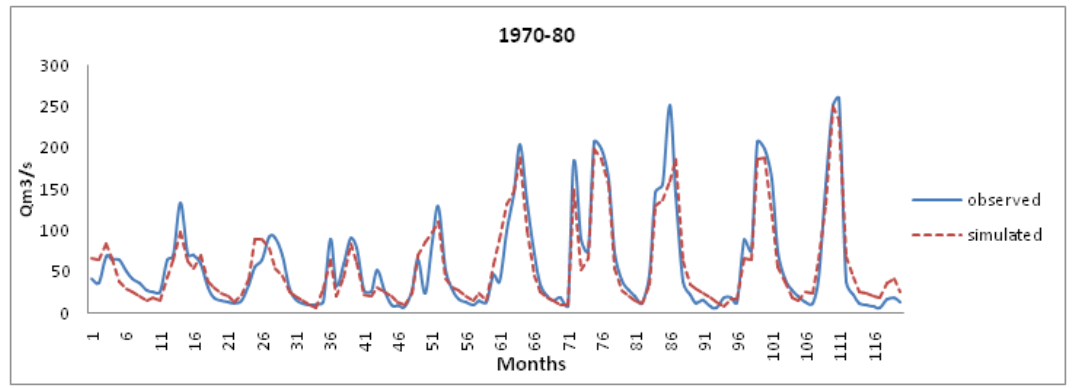

Figure 18. Values of runoff Maroon areas simulated and observed using the sufi2 program in calibration stage on a monthly basis in the first decade

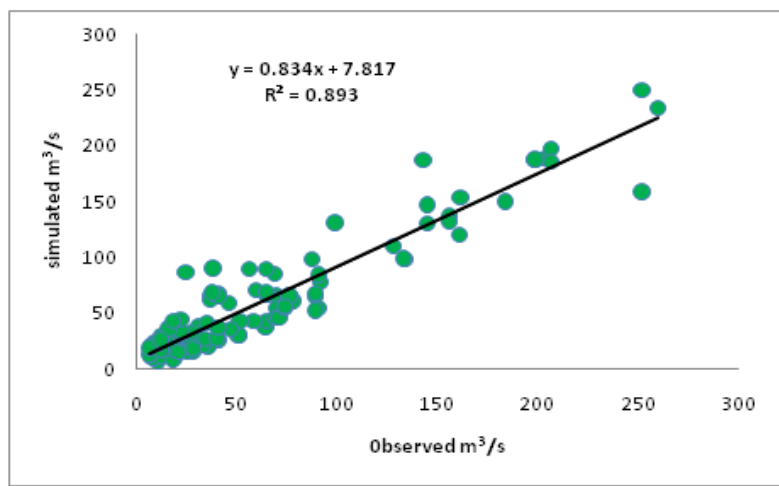

Figure 19. The correlation between simulated and observed runoff model calibration using the sufi2 program stage on monthly basis - the first decade period

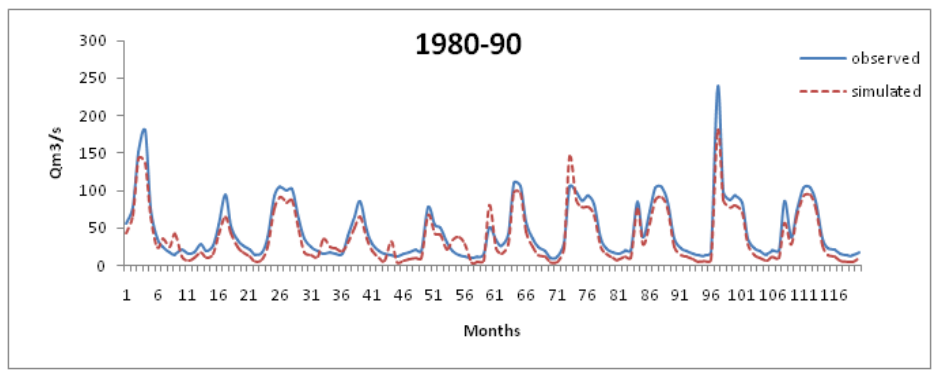

Figure 20. Values of simulated and observed runoff areas at the base of Maroon using the sufi2 program model calibration phase on a monthly basis - second decade period

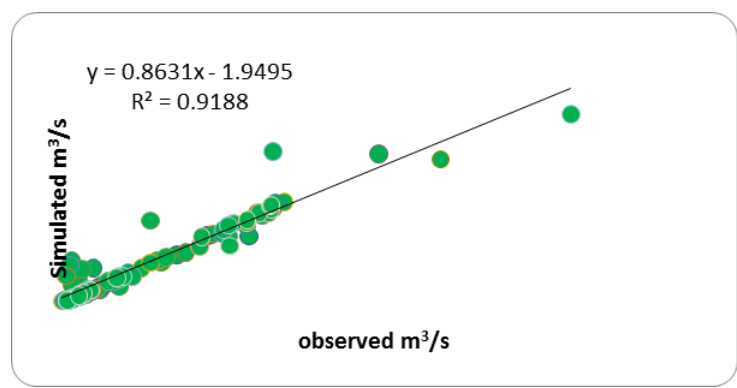

Figure 21. The correlation between simulated and observed runoff model calibration using the sufi2 program stage at the base monthly time period - second decade 


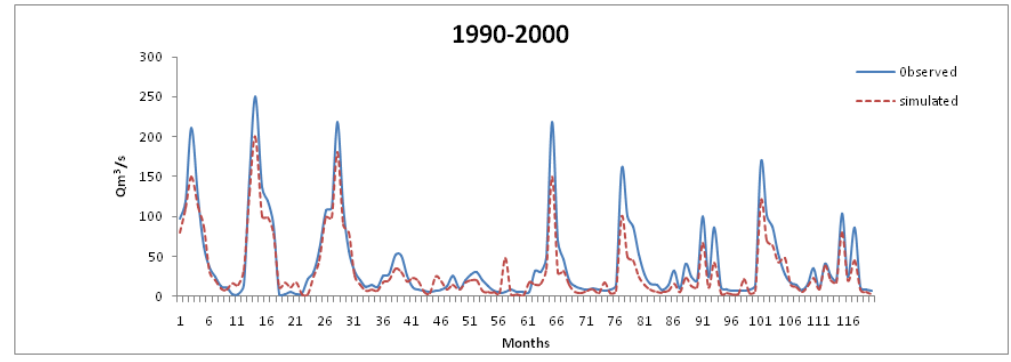

Figure 22. Observed and simulated runoff values of the Maroon basin by using the sufi2 program calibration model on a monthly basis - the third decade

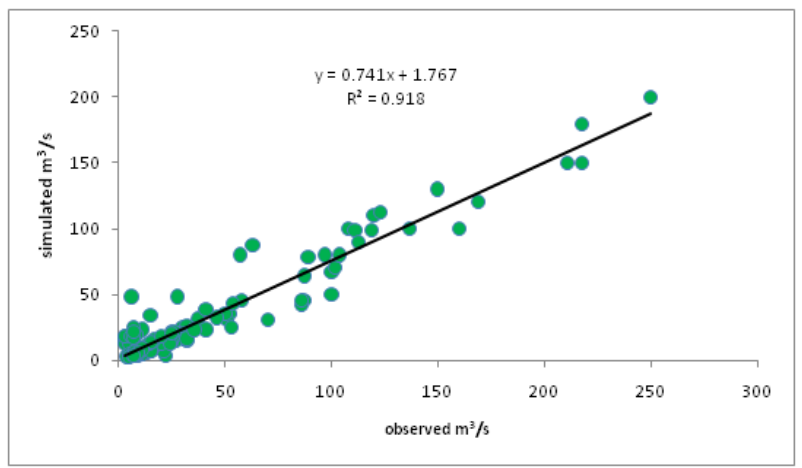

Figure 23. The correlation between simulated and observed runoff model calibration by using the sufi2 program stage on a monthly basis - third decade

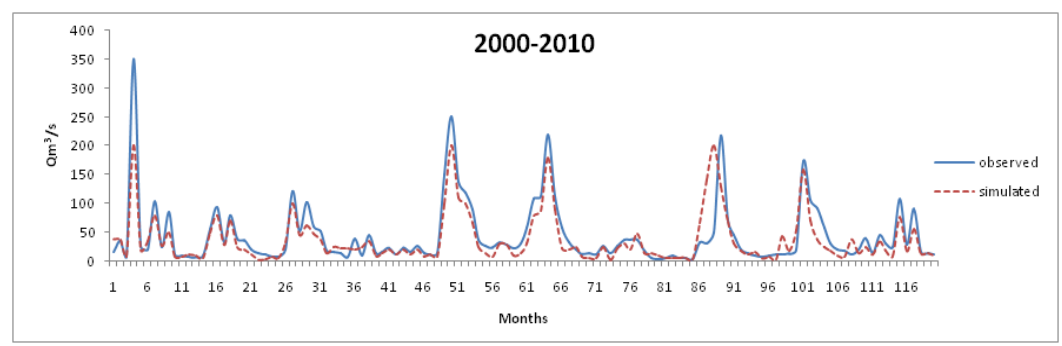

Figure 24. The values of simulated and observed runoff of the Maroon basin by using the sufi2 program model calibration on a monthly basis - fourth decade

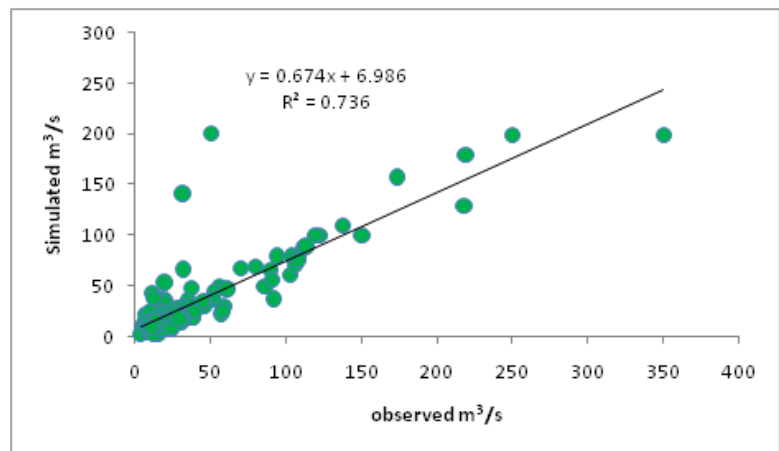

Figure 25. The correlation between simulated and observed runoff model calibration by using the sufi 2 program stage on a monthly basis - fourth decade 
Table 3. The final value parameters (amount or percentage changes) by using SUF12 program on a monthly basis

\begin{tabular}{c|c|c}
\hline Range & Parameter description & Parameter name \\
\hline $60-70$ & The primary SCS Curve Number for average moisture conditions (II) & CN2 \\
$15-30$ & Saturated hydraulic conductivity of the soil layer (mm/hr) & SOL_K \\
$0.01-0.1$ & Constant depletion of ground water days & ALPHA_BF \\
$10-150$ & The average length of the slope of the land in each HRU (m) & SLSUBBSN \\
$0-1$ & The minimum rate of snow melt during the year (mmH2O/0C-day) & SMFMN \\
$0.1-0.25$ & The maximum rate of snowmelt during the year (mmH2O/0C-day) & SMFMX \\
$0.1-0.2$ & Factor soil evaporation & ESCO \\
$0.2-0.4$ & Shallow or deep aquifer fed percent of non-enclosed table & RCHRG_DP \\
$2-3$ & Snow or rain turned to snow average air temperature & SFTMP \\
$80-95$ & Water kept up by vegetation (mmH2O) & CANMX \\
$0-0.5$ & The base temperature of melting snow & SMTMP \\
$0-150$ & The main river bed effective hydraulic conductivity (mm / hr) & CH-K2 \\
\hline
\end{tabular}

\section{Validation of the model}

In this research, Idnak hydrometric station was an aid and supplement for computational parameters required for the SWAT model during calibration and validation. In accordance to studies conducted by Omani et al., two-thirds of the available data for calibration and one-third was used for validation. Statistical and graphical simulation results indicate acceptable water flow for the period of calibration results at this stage. For validation of the model, optimized parameters were used in the calibration stage from the SWAT CUP software package and the SUFi2 program.

\section{Model evaluation}

To evaluate the performance of the SWAT model in the simulation of monthly discharge at Idnak hydrometric station, indicators were presented during calibration and validation based on the criteria for evaluating the accuracy of the simulation. Numerous researchers have recommended using several methods for parameter optimization and uncertainty analysis instead of one particular method (Abbaspour et al., 2004), (Abbaspour et al., 2007). This is the reason that for this study, the SUFi2 program was used in the form of an extension in the SWAT model bundle within the SWAT CUP software package. The usefulness of model was examined by coefficients such as pfactor, r-factor, R2, ENS, bR2, MSE and RMSE in the watershed outlet (Table 4). In this study, the Nash-Sutcliffe efficiency was used as an objective function for the model calibration and verification. P-factor index in watershed Maroon is from 0.72 to 0.92 for the monthly period variable. The greater the index, the more effective the simulation is. The value of this parameter in these areas is low which indicates great uncertainty in forecasts. One of the reasons for low p-factor is that the current value is greater than the values predicted by the model base. The results for the observed data are located outside the $95 \%$ prediction uncertainty ranges. Lack of information about the uptake and upstream water use is a reason for the incompetency of the base flow prediction model. Therefore, in order to reduce uncertainty in models, there is a need to use comprehensive data on water management in the studied area. R-factor is the average 
thickness of the band 95 PPU which is divided by the standard deviation measured data. The less the value of this index, the less the simulation is done with greater precision so that the optimal value is zero. This index regarding Maroon basin is a variable for monthly periods showed values of 0.93 to 90.2 during the calibration. Relatively small values of $\mathrm{p}$-factor and $\mathrm{r}$-factor in this basin on a monthly basis indicate good calibration and runoff in the basin and there is lower prediction uncertainty. The value of R2 (R2 coefficient multiplied by the coefficient of linear regression) using the SUFI2 program for calibration for the monthly period is 0.75 . The value of this coefficient for the validation period is 0.82 on a monthly basis. The Mean Square Error (MSE) is scaled to consider the random mean difference between simulation and observations. MSE and RMSE Square represent the value of these parameters which can be varied from zero to infinity and the optimal value is zero. In addition, these factors along with $\mathrm{E}_{\mathrm{NS}}$ and $\mathrm{R}_{2}$ coefficients were used to determine suitability. The optimal value of $R_{2}$ is one. Although, there is no specific rule as reported by (Santi et al., 2001) that 0.5 is not acceptable for hydrological models. According to Table 5, the index in the SUFI2 program at calibration period is 0.84 and for validation period 0.82 on a monthly basis. In general, according to the simulation results, the accuracy of the model for the basin hydrological process simulation was relatively good. Finally, this model can be used for future analyses of basins and sub-basins and to check the different components of the hydrological cycle.

Table 4. The statistical coefficients evaluation of the accuracy of the model to simulate the monthly runoff during calibration and validation

\begin{tabular}{c|c|c}
\hline \multicolumn{2}{c|}{ SUF12 } & \multirow{2}{*}{ The statistical indices } \\
\hline Validation & Calibration & P_factor \\
0.92 & 0.79 & R_factor \\
0.91 & 1.51 & $\mathrm{R}^{2}$ \\
0.86 & 0.85 & $\mathrm{E}_{\mathrm{NS}}$ \\
0.829 & 0.86 & $\mathrm{bR}^{2}$ \\
82.07 & 0.654 & $\mathrm{MSE}^{2}$ \\
9.05 & 58.88 & RMSE \\
\hline
\end{tabular}

\section{Conclusion}

One of the specific applications to examine different components of the hydrological cycle is to utilize the SWAT model based on different scenarios. The results of this study states that SUF12 program and the basic monthly runoff curve number are the most sensitive parameters. On the other hand, there is a direct relationship between this parameter and land use. Parameter CN2 (primary SCS Curve Number for average moisture conditions (II) and the slope 5\%) is a function of the soil permeability, land use and previous humidity conditions. The value of this parameter for different soil types and land use is different for each sub-basin. In general, increasing the amount of $\mathrm{CN} 2$ increases the volume of runoff water and reduces power losses, waterborne rivers and underground water resources, soil erosion and sediment changes (Setegn et al., 2010). The high sensitivity of this parameter indicates the important role of land use in these areas in the amount of runoff from the basin. A comparison of the effect of land 
use management options on different hydrological cycle components show different amounts of runoff over the past four decades. A pessimistic scenario occurs with the continuing damage to the state in land use regression and various increases of runoff amounts which decrease permeability and gullies to the shallow and deep aquifers, stream sub cortical and results in actual evapotranspiration. Figure 26 shows a comparison of the flow surface runoff, base flow and susceptibility of model to CN.

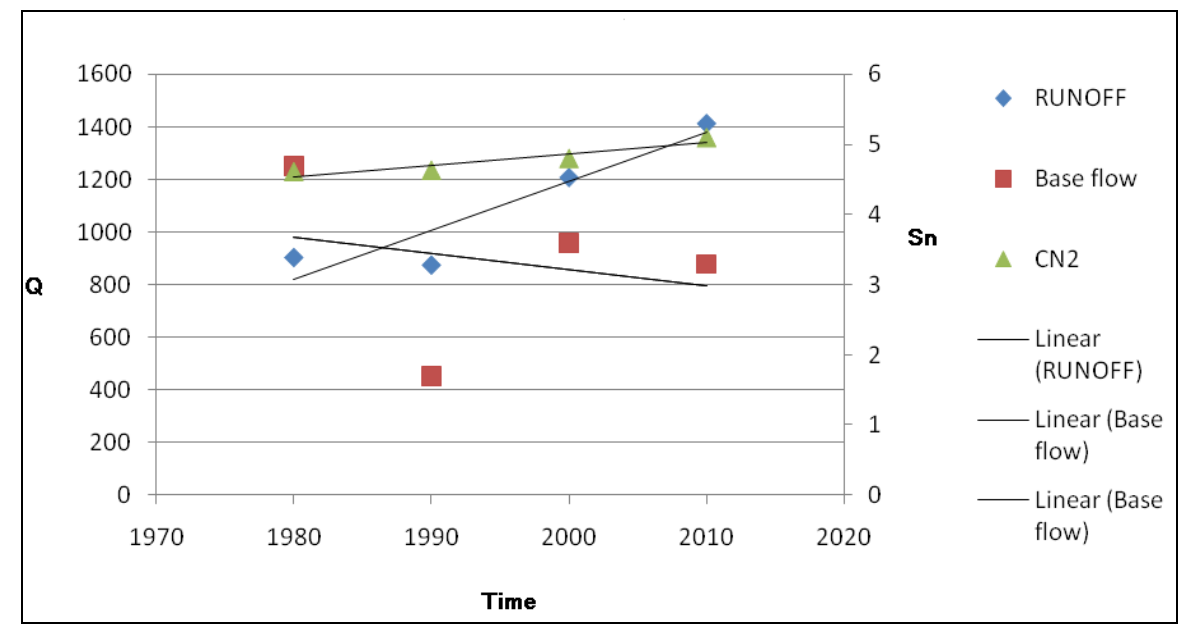

Figure 26. Comparison of the flow surface runoff, base flow and susceptibility of model to $C N$

As evident in each scenario, by changing land use, changes in runoff peak values should entail a positive trend for reducing the negative trend for an increase in peak flow and peak values. This is due to change in the type of vegetation, and the result is a change in the runoff curve number. In this case, by reducing the permeability, greater quantities of rainfall run off the surface. Thus, the hydrological response basin in a state of regression and degradation is more severe than in the user regenerative mode; Hence, the need to maintain the current state of the basin and improving land use is one of the basic strategies for managing surface runoff.

\section{REFERENCES}

[1] Abbaspour, K. C., Johnson, C. A., Vangenuchten, T. M. (2004): Estimating uncertain flow and transport parameters using a sequential uncertainty fitting procedure. - Vadose Zone Journal 3: 1340-1352.

[2] Abbaspour, K. C., Yang, J., Maximov, I., Siber, R., Bogner ,K., Mieleitner, J., Zobrist, J., Sirinsivasan, R. (2007): Modeling Hydrology and water quality in the per-alpine Thure watershed using SWAT. - Journal of Hydrology 333:413-430.

[3] Alavinia, M., Nasiri, F. (2010): Compare the HSPF model and SWAT model simulation of sediment (case study catchment area of the Abroo). - The fifth National Congress of Civil Engineering, Ferdowsi University of Mashhad.

[4] Anwar, N. S. (2010): Simulated Impact of land use dynamics on Hydrology during a 20ear-period of Deles Basin in Ethiopia. - TRITA-LWR Master Thesis, Department of Land and Water Resources Engineering, Royal Institute of Technology (KTH), Stockholm, Sweden, pp. 1-33.

[5] Beven, K. J. (2001): Rainfall-Runoff Modeling: the Primer. - Wiley, Chichester, UK. 
[6] Duan, Z., Song, X., Liu, J. (2009): Application of SWAT for sediment yield estimation in a mountainous agricultural basin. - Graduate University of Chinese Academy of Sciences (GUCAS), Conservation Sedny. 76: 501-521.

[7] Green, C. H., Tomer, M. D., Diluzio, M., Arnold, J. G., James, D. (2006): Hydrologic calibration of the soil and water assessment tool for a large tile-drained watershed in Iowa. - Transactions of the American Society of Agricultural and Biological Engineers (ASABE). 2(49): 411-413.

[8] Himesh, S., Rao, C., Mahajan, A. (2000): Calibration and Validation of Water Quality Model. - CSIR Centre for Mathematical Modelling and Computer Simulation, Technical Report CM 0002, Bangalore, India.

[9] Karlinger, M. R., Guertin, D. P., Troutman, B. M. (1998): Regression estimates for topological-hydrograph input. - J. Water Resour. 114: 446-456.

[10] Liu, Y. (2009): Automatic calibration of a rainfall-runoff model using a fast and elitist multi objective particle swarm algorithm. - Expert Systems with Applications 36: 95339538.

[11] Mirabzadeh, M., Globoidnia, M. (2005): The structure of mathematical modelsand theirapplication in groundwater systems. - Modeling Workshop onIrrigation andDrainage, The National Committee on Irrigation and Drainage. 18-20 November 2005, Tehran, Iran.

[12] Omani, N., Tajrishy, M., Abrishamchi, A. (2007): Modeling of a river basin using SWAT model and GIS. - International Conference on Managing Rivers in the 21 century, Reversid Kuching, Saravak, Malaysia, pp. 510-517.

[13] Palamuleni, L.G. (2011): Evaluating land cover change and its impact on hydrological regime in Upper Shire river catchment, Malawi. - Reg Environ Change 113:145-155.

[14] Phomcha, P., Wirojanagud, P., Vangpaisal, T., ..., Thaveevouthti, T. (2011): Predicting sediment discharge in an agricultural watershed: A case study of the Lam Sonthi watershed Thailand. - J of Science Asia 37: 43-50.

[15] Reungsang, P., Kanwar, R. S., Jha, M., Gassman, P. W., Ahmad, K., ..., Saleh, A. (2005): Calibration and Validation of SWAT for the Upper Maquoketa River Watershed. - Working Paper 05-WP 396, Center for Agricultural and Rural Development (CARD) at Iowa State University, pp. 1-19.

[16] Rostamian, R. (2006): Estimating runoff and sediment in Beheshtabad in North Karun Using SWAT2000. - Master of Science, Water Engineering, College of Agriculture, Isfahan University of Technology, pp. 43-48.

[17] Rostamian, R., Jaleha, A., Afyunia, M., Mousavian, S. F., Heidarpour, M., Jalalian, A., Abbaspour, K. C. (2010): Application of a SWAT model for estimating runoff and sediment in two mountainous basins in central Iran. - Hydrological Sciences Journal 53: 977-988.

[18] Salmani, H. (2011): Optimization parameters of rainfall - runoff in the semi-distributed model SWAT Ghazaghli basin in Golestan Province. - M.Sc. Thesis, Department of Rehabilitation Desert, Department of Natural Resources, Tehran University, pp. 234-236.

[19] Sangjun, I., Brannan, K. M., Mostaghimi, S., , Sang, M. K. (2007): Comparison of HSPF and SWAT models performance for runoff and sediment yield prediction. - Journal of Environmental Science and Health 11: 1561-1570.

[20] Sanjay, J. (2010): Simulation of runoff and sediment yield for a Himalayan watershed using SWAT model. - Journal of Water Resource and Protection 2: 267-281.

[21] Setegn, S. G., Dargahi, B., Srinivasan, R., ..., Melesse, A. M. (2010): Modeling of sediment yield from Anjeni-Gauged watershed, Ethiopia using SWAT model. - Journal of the American Water Resources Association (JAWRA) 46(3): 514-526.

[22] Spruill, C. A., Workman, S. R., ..., Taraba, J. L. (2000): Simulation of daily and monthly stream discharge from small watershed using the SWAT model. - Soil and Water Division of ASAE, pp. 1431-1440. 
[23] Water Resources Management Company of Iran (2009): Report on Updating Integration of Studies on Water Resources in Maroon Watershed, $3^{\text {rd }}$ ed. - Khuzestan Province Water and Electricity Organization (Public Joint Stock). Base Studies on Water Resources Assistance, pp. 177-189.

[24] Willems, P. (2009): A time series tool to support the multi-criteria performance evaluation of rainfall-runoff models. - Environmental Modelling \& Software 24: 311321.

[25] Zhang, X., Srinivasan, R., Van Liew, M. (2008): Multi-site calibration of the SWAT model for Hydrologic modeling. - Soil \& Water Division of ASABE, American Society of Agricultural and Biological Engineers 51(6): 2039-2049. 